\title{
Subcellular FIH-1 expression patterns in invasive breast cancer in relation to $\mathrm{HIF}-1 \alpha$ expression
}

\author{
Agon Hyseni • Petra van der Groep • \\ Elsken van der Wall • Paul J. van Diest
}

Accepted: 27 June 2011 /Published online: 6 July 2011

(C) The Author(s) 2011. This article is published with open access at Springerlink.com

\begin{abstract}
Background Hypoxia Inducible Factor- $1 \alpha$ (HIF-1 $\alpha)$ expression in breast cancer is associated with a poor clinical outcome. HIF- $1 \alpha$ shows two expression patterns: the canonical poor prognosis hypoxia-related perinecrotic pattern and a diffuse expression pattern that seems to have less downstream effects and is clearly associated with poor survival. Factor-inhibiting hypoxia-inducible factor 1 (FIH1) inhibits HIF-1 activity by hydroxylating the C-terminal trans-activation domain of the HIF- $1 \alpha$ subunit, thus preventing HIF-1 from recruiting co-activators $\mathrm{CPB} / \mathrm{p} 300$, which are important for inducing the transcription of target genes. The aim of this study was to investigate the expression patterns of FIH-1 in breast cancer and evaluate the relationship between FIH-1 and HIF- $1 \alpha$ expression in breast cancer as a possible explanation for apparently less downstream effects of diffuse HIF- $1 \alpha$ expression.

Methods Tissue sections from 92 consecutive invasive breast carcinomas were stained by immunohistochemistry for FIH-1, HIF-1 $\alpha$, glucose transporter 1 (GLUT-1) and carbonic anhydrase IX (CAIX).

Results 45 cases overexpressed HIF-1 $1 \alpha, 5$ of which in a perinecrotic fashion while FIH-1 was positive in 73 of the 92 cases studied. Contrary to our expectations, three out of five cases with perinecrotic HIF- $1 \alpha$ expression were also positive for FIH1. Cytoplasmic FIH-1 correlated with HIF-1 $\alpha$ expres-
\end{abstract}

\footnotetext{
A. Hyseni $\cdot$ P. J. van Diest $(\bowtie)$

Department of Pathology, University Medical Centre Utrecht, PO Box 85500, 3508 GA Utrecht, The Netherlands

e-mail: P.J.vanDiest@umcutrecht.nl

P. van der Groep · E. van der Wall

Division of Internal Medicine and Dermatology,

University Medical Centre Utrecht,

Utrecht, The Netherlands
}

sion $(P=0.03)$ and tumor grade $(P=0.01)$. HIF-1 $\alpha$ overexpression predicted poorer prognosis as usual $(P=0.02)$. FIH expression had no additional prognostic value to HIF-1 $\alpha$. Conclusions FIH1 is expressed in the majority of invasive breast carcinomas and shows distinct subcellular localization patterns. FIH-1 expression does not seem to explain the proposed functional differences between diffuse and perinecrotic HIF- $1 \alpha$ expression in breast cancer.

Keywords Breast cancer · Hypoxia ·

Immunohistochemistry $\cdot$ Prognosis

\section{Introduction}

Due to the increased rate of cell multiplication and the inadequate supply of oxygen due to lagging angiogenesis, hypoxic conditions are frequently present in breast carcinoma [1]. To survive in this environment, cancer cells induce the transcription of a complex set of genes involved in numerous cellular survival pathways. The most important of these pathways include angiogenesis, glycolysis, $\mathrm{pH}$ regulation and metastasis [2].

The principal molecule orchestrating the cellular response to hypoxia is Hypoxia Inducible Factor-1 (HIF-1) [3, 4]. Structurally, HIF-1 is a heterodimer consisting of the highly regulated HIF- $1 \alpha$ and constitutively expressed HIF- $1 \beta$ subunits. Once these two subunits dimerize, HIF-1 can bind to hypoxia response elements (HREs) in the promoters of target genes and induce their transcription [5]. However, under normoxic conditions, the HIF- $1 \alpha$ subunit is continuously degraded, a process which starts with a set of enzymes called prolyl hydroxylase domain enzymes (PHDs). PHDs hydroxylate HIF- $1 \alpha$ at proline residues P402 and P564 in the oxygen dependent degradation domain (ODDD), conse- 
Table 1 Histological types of invasive breast cancers in the study group

\begin{tabular}{lcc}
\hline & Frequency & Percentage \\
\hline Invasive ductal carcinoma & 60 & $65 \%$ \\
Invasive lobular carcinoma & 14 & $15 \%$ \\
Tubular carcinoma & 10 & $11 \%$ \\
Ductal-lobular carcinoma & 4 & $4 \%$ \\
Metaplastic & 2 & $2 \%$ \\
Invasive cribriform & 2 & $2 \%$ \\
\hline
\end{tabular}

quently, this domain is recognized by the Von-Hippel Lindau Protein and targeted for degradation by the proteosome [5].

In multiple cancers, HIF $1 \alpha$ has been implicated in prognosis $[6,7]$. In breast cancer, HIF1 has been implicated in sporadic [8] and hereditary carcinogenesis [9] and is associated with metastases formation [10], angiogenesis [11], poor clinical outcome $[12,13]$ and resistance to therapy $[14,15]$.

In cancers like breast $[8,11,12,16]$ and endometrium [6, 17, 18], HIF-1 $\alpha$ showed two expression patterns: a hypoxia-related perinecrotic expression pattern and a diffuse expression pattern. In invasive breast cancer, the perinecrotic HIF- $1 \alpha$ expression pattern is associated with expression of the HIF- $1 \alpha$ downstream genes Glut-1 and CA IX, while the diffuse HIF- $1 \alpha$ expression pattern lacks this association and points to non-functional HIF- $1 \alpha$ expression. Furthermore, perinecrotic HIF- $1 \alpha$ indicated a poor prognosis, while diffuse HIF-1 $\alpha$ expression is prognostically better [19].

Apparently, the effects of HIF-1 $\alpha$ depend not only on the expression level but also on the expression pattern. The mechanisms of the seemingly non-functional diffuse HIF-1 expression have not fully been elucidated. Amplification of the HIF-1 $\alpha$ gene as observed in prostate cancer [20] appeared to be absent in invasive breast cancer [21], as were mutations in the ODDD [22]. In contrast, p300 and p53 levels did seem to determine activation of HIF-1 downstream targets in invasive breast cancer [23].

In addition to the control provided with hydroxylation by PHDs and subsequent proteosome degradation, transcription induction of HIF- $1 \alpha$ is controlled by hydroxylation of a single conserved aspariginyl residue at the C-terminal trans-activation domain (C-TAD). This hydroxylation is conducted by factor inhibiting hypoxia-inducible factor (FIH) and is of particular importance as C-TAD is the binding site for $\mathrm{CPB} / \mathrm{p} 300$, essential co-activators required for transcription induction [24]. In this manner, FIH-1 provides an additional level of control to PHDs and prevents HIF-1 activity at normoxia. More importantly, FIH-1 is able to exercise the control of HIF-1 even under severe hypoxic conditions, when PHD enzymes fail to do so [25]. In renal cell cancer, nuclear FIH expression independently predicted overall survival [26]. In breast cancer, FIH-1 expression has been analysed in a limited number of studies [14, 27]. Since FIH-1 is an important regulator of HIF-1 activity, the purpose of this study was to analyze the expression patterns of FIH-1 in invasive breast cancer as a possible explanation for the non-functionality of diffuse HIF-1 $\alpha$ expression.

\section{Materials and methods}

The study group comprised of 92 consecutive invasive breast carcinomas that were collected from the archive of the Department of Pathology of the University Medical Center Utrecht, The Netherlands. Age, tumor size, and ER, PR and HER2 status were collected from the pathology reports. Histological type was revised according to the WHO. Mitotic counting was done as before [28] and subsequent grading was performed according to Elston [29]. Use of left over tissue for research is part of the standard treatment contract with patients in our hospital [30].

The majority of the tumors were classified as invasive ductal carcinoma of no special type (65\%; Table 1). Median tumor size was $2 \mathrm{~cm}$. Median age was $56.39 \%$ of the tumors were classified as grade $1,32 \%$ as grade 2 and $28 \%$ as grade $3.87 \%$ of the tumors were ER positive while $60 \%$ were PR positive. Only 3 cases were positive for HER2.

\subsection{Immunohistochemistry}

Immunohistochemistry (IHC) was performed on $4 \mu \mathrm{m}$-thick sections. After de-paraffination and rehydration, endogenous peroxidase blockage ensued. For HIF-1 $\alpha$, antigen retrieval was achieved by heating the sections in EDTA buffer ( $\mathrm{pH} \mathrm{9.0)} \mathrm{at} \mathrm{boiling} \mathrm{temperature} \mathrm{for} 20 \mathrm{~min}$. After a cooling down period of $30 \mathrm{~min}$ in the same buffer, protein block was applied (Novolink Kit, Novocastra Laboratories,
Table 2 Details of the antibodies applied

\begin{tabular}{lllll}
\hline Antibody & Manufacturer & Antigen retrieval & Incubation & Dilution \\
\hline FIH 1 & Novus Biologicals & 20' Citrate pH 6.0 buffer & 1 h at room temperature & $1: 100$ \\
HIF-1 $\alpha$ & Biosciences Pharmingen & 20' EDTA pH 9.0 buffer & overnight at $4{ }^{\circ} \mathrm{C}$ & $1: 50$ \\
CAIX & ABCAM & 20' Citrate pH 6.0 buffer & 1 h at room temperature & $1: 1000$ \\
GLUT-1 & Dako & 20' Citrate pH 6.0 buffer & 1 h at room temperature & $1: 200$ \\
\hline
\end{tabular}


Table 3 Correlation analysis between HIF- $1 \alpha$ expression and GLUT1, ER, PR, HER2 and tumor type and grade (chi-square test). NB: Not all stainings could be successfully performed for all cases

\begin{tabular}{llrrr}
\hline & & \multicolumn{2}{c}{ HIF-1 $\alpha$ overexpression } & \\
\cline { 3 - 4 } & & Negative & Positive & \multirow{2}{*}{$P$ value } \\
\hline \multirow{2}{*}{ GLUT-1 } & Negative & 37 & 31 & 0.1 \\
& Positive & 8 & 16 & \\
ER & Negative & 2 & 10 & 0.03 \\
& Positive & 42 & 37 & \\
PR & Negative & 15 & 22 & 0.3 \\
& Positive & 28 & 25 & \\
HER2 & Negative & 44 & 43 & 1 \\
& Positive & 1 & 2 & \\
CAIX & Negative & 27 & 11 & $<0.01$ \\
& Positive & 18 & 36 & \\
Grade & 1 & 25 & 11 & 0.00 \\
& 2 & 16 & 14 & \\
& 3 & 4 & 22 & \\
Type & Ductal/metaplastic & 26 & 36 & 0.05 \\
& Tubular/lobular/ & 19 & 11 & \\
& cribriform & & & \\
\hline
\end{tabular}

Newcastle upon Tyne, UK) and sections were subsequently incubated overnight with the primary antibody at $4^{\circ} \mathrm{C}$ (Table 2). Thereafter, to detect HIF-1 $\alpha$, the Novolink Kit (Novocastra) was applied according to the manufacturer's instructions. For FIH-1, antigen retrieval was achieved by heating the sections in citrate buffer $(\mathrm{pH}$ 6.0) at boiling temperature for $20 \mathrm{~min}$. After a cooling down period of $30 \mathrm{~min}$ in the same buffer, the sections were incubated with the primary antibody (Table 2). Incubation was applied for $1 \mathrm{~h}$ at room temperature, followed by the application of the Powervision Kit (Immunologic, Duiven, The Netherlands) for $30 \mathrm{~min}$. All slides were developed with diaminobenzidine for $10 \mathrm{~min}$. Finally, the sections were counterstained in hematoxylin and mounted. IHC for GLUT-1 and CA IX was performed as described before [17].

For HIF- $1 \alpha$, the percentage of dark brown nuclei was estimated as before $[8,12,19]$. For GLUT1 and CA IX, the presence of membranous or cytoplasmic expression was noted as well as the expression pattern (perinecrotic versus diffuse).

An experienced pathologist (PJvD) performed the scoring of FIH-1 in a blinded fashion with regards to other biomarkers and clinicopathological data. The percentage of the nuclei stained was estimated, and the intensity of cytoplasmic staining was semiquantitatively scored as negative $(0), 1+, 2+$ or $3+$.

\subsection{Statistics}

For HIF- $1 \alpha$, cases with $\geq 1 \%$ of positive stained nuclei were considered as showing overexpression as before [19]. The threshold for FIH-1 cytoplasmic positivity was set at $\geq 2$, while the threshold for FIH-1 nuclear positivity was set at $\geq 10 \%$. Therefore, tumors with a FIH- 1 cytoplasmic staining of an intensity $\geq 2$ or with $\geq 10 \%$ of the nuclei stained positive were regarded as positive in the statistical analysis.
Fig. 1 Expression patterns of FIH-1: a FIH-1 expression in normal breast tissue; $\mathbf{b}$ nuclear FIH-1 expression of breast carcinoma cells; c cytoplasmic FIH-1 expression of breast carcinoma cells; d FIH-1 expression in both the nucleus and cytoplasm of breast carcinoma cells
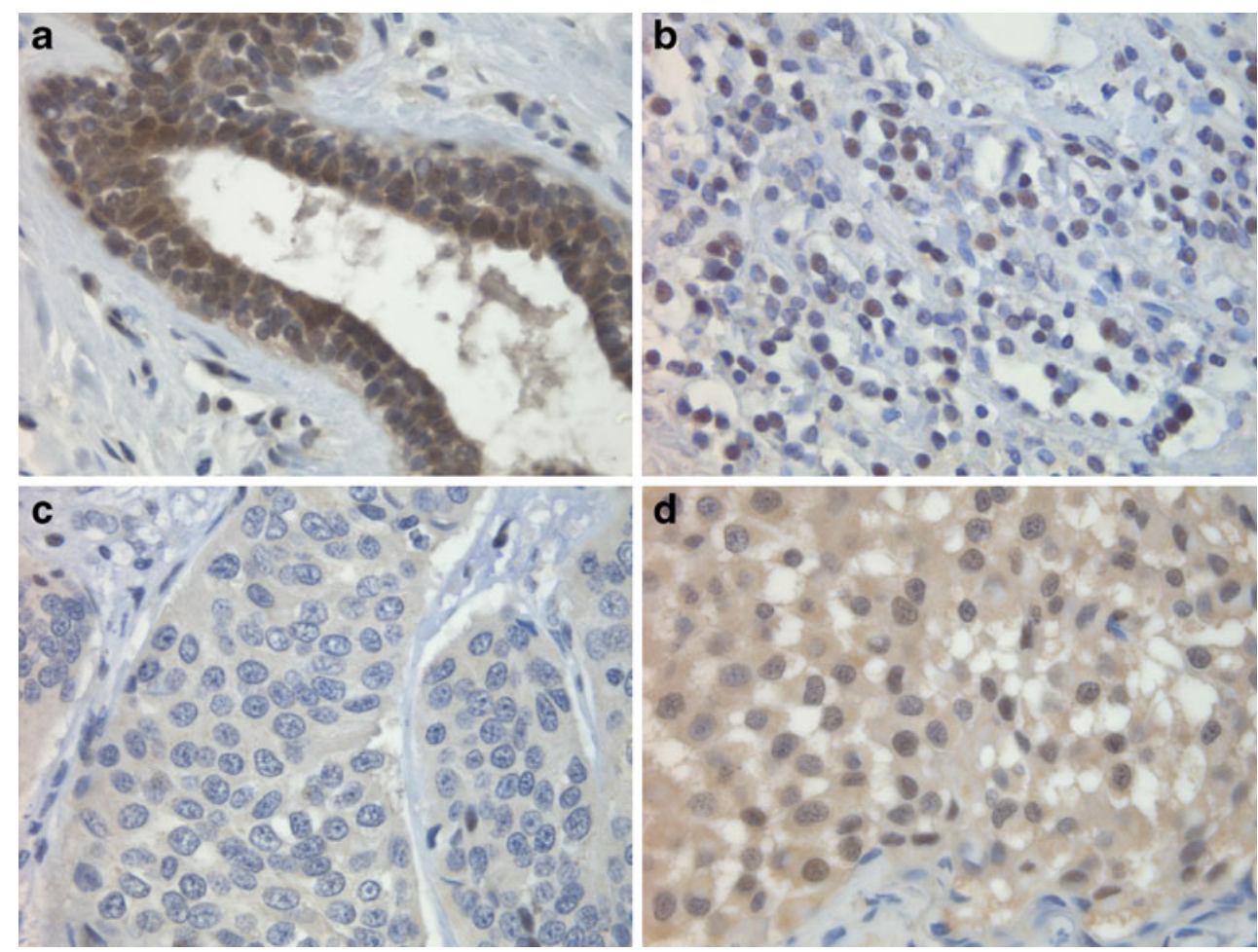
Correlations between HIF- $1 \alpha$, FIH-1 and other markers were evaluated using the Chi-square test. A Mann-Whitney Test was used to analyze differences in HIF-1 $\alpha$ and FIH-1 expression with regards to age and tumor size. For univariate recurrence free survival analysis, Kaplan Meier curves were plotted and differences between the curves were evaluated by the logrank test. Multivariate survival analysis was done by Cox regression. All statistics were done using SPSS version 15.0 (SPSS Inc, Chicago, USA).

\section{Results}

As expected, HIF- $1 \alpha$ was more often expressed in ductal/ metaplastic cases $(36 / 62)$ compared to tubular/lobular/ cribriform cancers $(11 / 30)(P=0.05)$ and correlated with tumor grade and a worse prognosis (Table 3 ).

FIH-1 was expressed in luminal cells of the normal breast and showed both nuclear and cytoplasmic expression (Fig. 1a). In cancer cases, FIH-1 was expressed in 79\% (73/ 92) of the cases and showed distinct subcellular expression patterns (Table 4): in the nucleus 36/92 (39\%; Fig. 1b), in the cytoplasm 21/92 (23\%; Fig. 1c) or both $16 / 92(17 \%$; Fig. 1d). Cytoplasmic FIH-1 expression did not correlate to any of the other biomarkers except that the group of tubular/lobular/cribriform cancers showed less often high expression $(P=0.02)$.

Three cases expressing HIF- $1 \alpha$ in a perinecrotic fashion also expressed FIH-1 (Fig. 2), the remaining two were negative. Exclusive nuclear FIH-1 expression showed an inverse correlation with tumor grade $(P=0.01)$. Furthermore, cytoplasmic expression of FIH-1 showed significant correlations to HIF-1 $\alpha(P=0.03)$, tumor grade $(P=0.01)$ and a trend for worse prognosis $(P=0.1)($ Fig. 3$)$. In multivariate survival analysis, cytoplasmic FIH expression had no additional prognostic value to HIF-1 $\alpha$.

\section{Discussion}

HIF-1 $\alpha$ plays a pivotal role in cellular adaptation to the hypoxic environment and as such, is crucial for the interaction between cells and the environment in which

Table 4 Subcellular localization patterns of FIH-1 in invasive breast cancer

\begin{tabular}{lc}
\hline Subcellular localization & Frequency/Percentage \\
\hline Negative & $19(21 \%)$ \\
Exclusively nuclear & $36(39 \%)$ \\
Exclusively cytoplasmic & $21(23 \%)$ \\
Both nuclear and cytoplasmic & $16(17 \%)$ \\
\hline
\end{tabular}

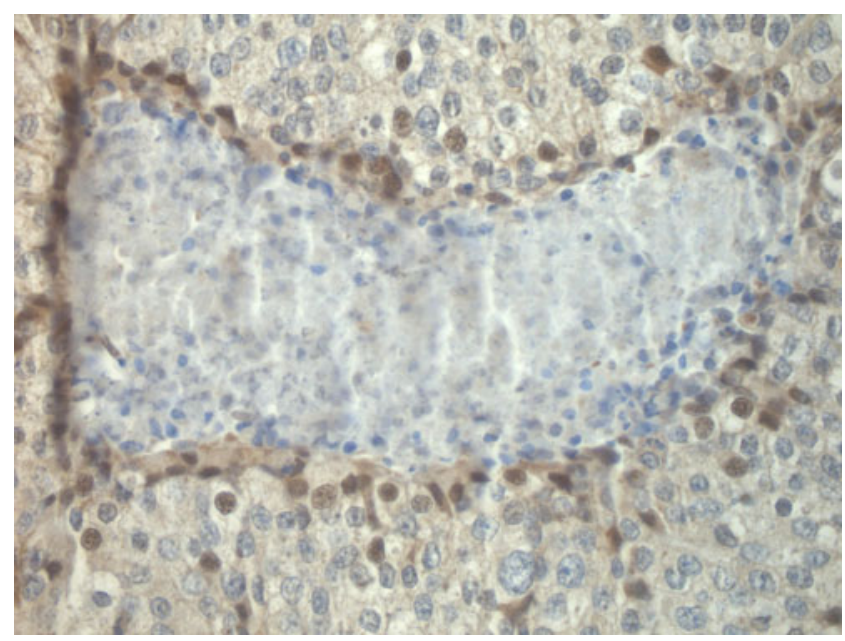

Fig. 2 Perinecrotic nuclear FIH-1 expression in an invasive breast cancer that also showed perinecrotic HIF- $1 \alpha$ overexpression

they function. Unfortunately, cancerous cells have grown to use the same HIF- $1 \alpha$ mechanisms and by doing so, are able to adapt and survive the hostile environment present in tumor tissues. Not surprisingly, HIF- $1 \alpha$ expression has been shown to be higher in poorly differentiated lesions and is associated with increased proliferation and metastasis $[8$, $13,31]$. In breast cancer however, HIF- $1 \alpha$ characteristically shows two different expression patterns: perinecrotic, apparently related to the severe hypoxia causing the necrosis, and a diffuse expression pattern where breast cancer cells stain widely and extensively without obvious correlation to local changes in oxygen tension. More importantly, these two expression patterns of HIF- $1 \alpha$ showed differences in the activation of downstream target genes and survival in a previous study [19]. Since the activity of HIF-1 $\alpha$ is highly regulated, it is plausible to

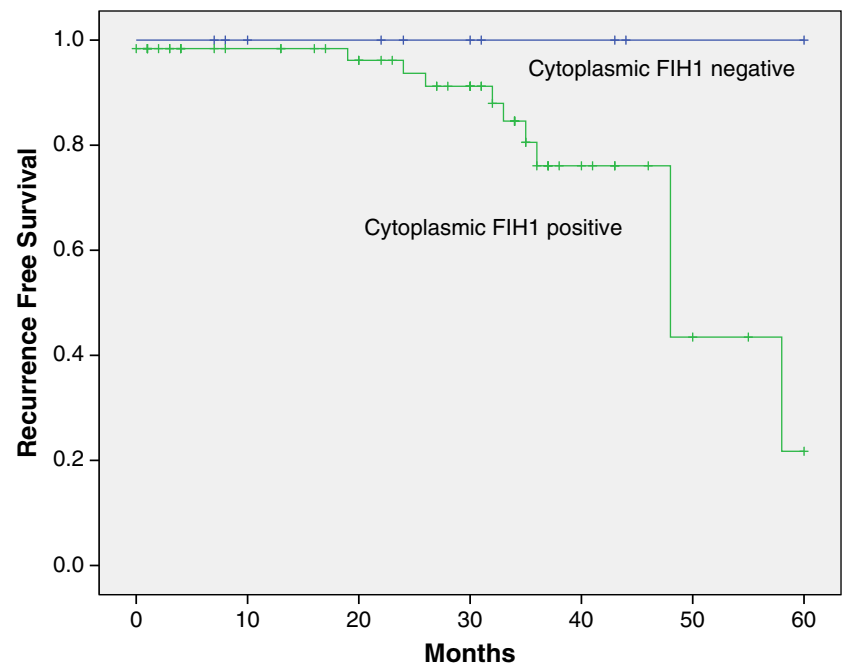

Fig. 3 Kaplan-Meier recurrence free survival curves for patients with or without FIH-1 cytoplasmic expression $(P=0.1)$ 
assume that the explanation for differences between the HIF- $1 \alpha$ expression patterns could lie in the regulation of its activity. Since FIH-1 is an important factor regulating HIF-1 transcriptional activity, even after PHDs and in severe hypoxia [25], we hypothesized that the loss of FIH-1 expression might provide an explanation for the putative functional differences between perinecrotic and diffuse patterns of HIF- $1 \alpha$ expression in breast cancer.

In accordance with previous studies [8, 11, 12, 19], we find that HIF- $1 \alpha$ expression is associated with higher tumor grade and poor prognosis. FIH-1 was expressed in the majority of the invasive breast carcinomas analyzed in the present study. Contrary to our expectations, FIH1 was positive in three out of five cases with perinecrotic HIF- $1 \alpha$ expression and we occasionally observed FIH-1 expression in perinecrotic cells overexpressing HIF-1 $\alpha$ (Fig. 2). Furthermore, we did not observe complete loss of FIH1 in any of the cases analyzed, indicating that FIH-1 expression is not the likely explanation for the differences between the HIF- $1 \alpha$ expression patterns mentioned.

Previous studies have reported expression of FIH1 in the cytoplasm and nuclei of cancerous cells [26, 27, 32-34]. We observe the same, with a significant number of cases showing predominantly nuclear or predominantly cytoplasmic expression. Since exclusive cytoplasmic presence of FIH-1 correlated with HIF- $1 \alpha$ expression, tumor grade and tended to indicate worse prognosis (Fig. 3), we supposed that FIH expression might have an additional prognostic value to HIF- $1 \alpha$. However, multivariate analysis showed this was not the case.

Associations between cytoplasmic FIH-1 expression and tumor aggressiveness have been shown for breast [27] and pancreatic endocrine tumors [34]. This contradicts to a certain degree what we know so far about the biology of FIH1, which points that FIH1 plays a tumor suppressor role and that its loss is expected to be a carcinogenic event. Since we did not observe a complete loss of FIH1 in any of our study cases, it rather seems that the subcellular localization of FIH-1 is of overriding importance.

While abundance of FIH-1 expression is regulated through proteosome degradation $[35,36]$, it seems that FIH-1 is rather constitutively expressed in various tissues, as shown for normal breast tissue in the present study. FIH1 is functional in the cytoplasm where it hydroxylates HIF$1 \alpha$, prevents it from recruiting coactivators like $\mathrm{CPB} / \mathrm{p} 300$ and hampers efficient transcription induction of HIF- $1 \alpha$ target genes. Though FIH-1 might be able to shuttle between the cytoplasm and the nucleus due to its small molecular weight, hypoxia has not been shown to influence its sub-cellular localization [32]. An interesting study by Zheng et al. showed that HIF-1 $\alpha$ is not the only substrate of FIH-1 and that FIH-1 hydroxylates the Notch intracellular domain (ICD) as well [37]. The Notch pathway is involved in many pivotal aspects of cellular fate like proliferation differentiation and cell death [38-40]. FIH-1 not only negatively regulates Notch ICD, but also influences the intracellular localization of FIH-1 by recruiting FIH-1 into the nucleus [37]. By sequestering FIH-1 away from HIF-1 $\alpha$ and potentiating the cellular hypoxic response, the Notch ICD might influence the phenotype of cancerous cells. Therefore, it is tempting to speculate that although there might be an increase in the hypoxic response, in tumors with exclusive nuclear localization of FIH-1, Notch signaling is abrogated.

In conclusion, expression patterns of FIH-1 do not seem to explain the proposed functional differences between diffuse and perinecrotic HIF- $1 \alpha$ expression in breast cancer. However, FIH is expressed in the majority of invasive breast carcinomas and shows distinct subcellular localization patterns related with tumor grade and HIF-1 $\alpha$ overexpression. The mechanisms behind this need to be further elucidated, especially with regards to the possible interaction with the Notch signaling pathway.

Open Access This article is distributed under the terms of the Creative Commons Attribution Noncommercial License which permits any noncommercial use, distribution, and reproduction in any medium, provided the original author(s) and source are credited.

\section{References}

1. P. Vaupel, K. Schlenger, C. Knoop, M. Höckel, Oxygenation of human tumors: evaluation of tissue oxygen distribution in breast cancers by computerized $\mathrm{O} 2$ tension measurements. Canc. Res. $\mathbf{5 1}$ (12), 3316-3322 (1991)

2. A.L. Harris, Hypoxia-a key regulatory factor in tumour growth. Nat. Rev. Canc. 2(1), 38-47 (2002)

3. G.L. Semenza, Regulation of mammalian O2 homeostasis by hypoxia-inducible factor 1. Annu. Rev. Cell Dev. Biol. 15, 551578 (1999)

4. A. Greijer, P. van der Groep, D. Kemming, A. Shvarts, G. Semenza, G. Meijer, M. van de Wiel, J. Belien, P. van Diest, E. van der Wall, Up-regulation of gene expression by hypoxia is mediated predominantly by hypoxia-inducible factor 1 (HIF-1). J. Pathol. 206, 291-304 (2005)

5. G.L. Wang, B.H. Jiang, E.A. Rue, G.L. Semenza, Hypoxiainducible factor 1 is a basic-helix-loop-helix-PAS heterodimer regulated by cellular O2 tension. Proc. Natl. Acad. Sci. USA 92 (12), 5510-5514 (1995)

6. L. Seeber, N. Horree, P. van der Groep et al., Perinecrotic HIF-1 alpha expression and necrosis predict prognosis in patients with endometrioid endometrial carcinoma. Cell. Oncol. 30, 158 (2008)

7. T. Fillies, R. Werkmeister, P.J. van Diest, B. Brandt, U. Joos, H. Buerger, HIF1-alpha overexpression indicates a good prognosis in early stage squamous cell carcinomas of the oral floor. BMC Canc. 5, 84 (2005)

8. R. Bos, H. Zhong, C.F. Hanrahan, E.C.M. Mommers, G.L. Semenza, H.M. Pinedo, M.D. Abeloff, J.W. Simons, P.J. van Diest, E. van der Wall, Levels of hypoxia-inducible factor-1 alpha during breast carcinogenesis. J. Natl. Canc. Inst. 93(4), 309-14 (2001) 
9. P. van der Groep, A. Bouter, F.H. Menko, E. van der Wall, P.J. van Diest, High frequency of HIF-1alpha overexpression in BRCA1 related breast cancer. Breast Canc. Res. Treat. 111(3), 475-480 (2008)

10. U. Woelfle, J. Cloos, G. Sauter, L. Riethdorf, F. Jänicke, P. Van Diest, R. Brakenhoff, K. Pantel, Molecular signature associated with bone marrow micrometastasis in human breast cancer. Canc. Res. 63, 5679-5684 (2003)

11. R. Bos, P.J. Van Diest, J.S. De Jong, P. Van der Groep, P. Van der Valk, E. Van der Wall, Hypoxia-inducible factor-1a is associated with angiogenesis and expression of bFGF, PDGF-BB, and EGFR in invasive breast cancer. Histopathology 46, 31-36 (2005)

12. R. Bos, P. Van Der Groep, A.E. Greijer, A. Shvarts, S. Meijer, H. M. Pinedo, G.L. Semenza, P.J. Van Diest, E. Van Der Wall, Levels of hypoxia-inducible factor-1alpha independently predict prognosis in patients with lymph node negative breast carcinoma. Cancer 97, 1573-1581 (2003)

13. J.P. Dales, S. Garcia, S. Meunier-Carpentier, L. Andrac-Meyer, O. Haddad, M.N. Lavaut, C. Allasia, P. Bonnier, C. Charpin, Overexpression of hypoxia-inducible factor HIF-1alpha predicts early relapse in breast cancer: retrospective study in a series of 745 patients. Int. J. Canc. 116(5), 734-739 (2005)

14. E.Y. Tan, M. Yan, L. Campo, C. Han, E. Takano, H. Turley, I. Candiloro, F. Pezzella, K.C. Gatter, E.K. Millar, S.A. O'Toole, C. M. McNeil, P. Crea, D. Segara, R.L. Sutherland, A.L. Harris, S.B. Fox, The key hypoxia regulated gene CAIX is upregulated in basal-like breast tumours and is associated with resistance to chemotherapy. Br. J. Canc. 100(2), 405-411 (2009)

15. A.E. Greijer, M.C. De Jong, G.L. Scheffer, A. Shvarts, P.J. Van Diest, E. Van der Wall, Hypoxia-induced acidification causes mitoxantrone resistance not mediated by drug transporters in human breast cancer cells. Cell. Oncol. 27, 43-49 (2005)

16. R. Bos, J.J.M. van der Hoeven, E. van der Wall, P. van der Groep, P.J. van Diest, E.F.I. Comans, U. Joshi, G.L. Semenza, O.S. Hoekstra, A.A. Lammertsma, C.F.M. Molthoff, Biologic correlates of 18 fluorodeoxyglucose uptake in human breast cancer measured by positron emission tomography. J. Clin. Oncol. 20, 379-387 (2002)

17. N. Horree, P.J. van Diest, P. van der Groep, D.M. Sie-Go, A.P. Heintz, Hypoxia and angiogenesis in endometrioid endometrial carcinogenesis. Cell. Oncol. 29, 219-227 (2007)

18. N. Horree, E. Gort, P. van der Groep, A. Heintz, M. Vooijs, P. van Diest, Hypoxia-inducible factor 1alpha is essential for hypoxic p27 induction in endometrioid endometrial carcinoma. J. Pathol. 214, 38-45 (2008)

19. M.M. Vleugel, A.E. Greijer, A. Shvarts, P. van der Groep, M. van Berkel, Y. Aarbodem, H. van Tinteren, A.L. Harris, P.J. van Diest, E. van der Wall, Differential prognostic impact of hypoxia induced and diffuse HIF-1alpha expression in invasive breast cancer. J. Clin. Pathol. 58(2), 172-177 (2005)

20. O.R. Saramäki, K.J. Savinainen, N.N. Nupponen, O. Bratt, T. Visakorpi, Amplification of hypoxia-inducible factor lalpha gene in prostate cancer. Canc. Genet. Cytogenet. 128(1), 31-34 (2001)

21. M.M. Vleugel, R. Bos, H. Buerger, P. Van der Groep, O.R. Saramäki, T. Visakorpi, E. Van der Wall, P.J. Van Diest, No amplifications of hypoxia-inducible factor-1alpha gene in invasive breast cancer: a tissue microarray study. Cell. Oncol. 26, 347-351 (2004)

22. M.M. Vleugel, A.E. Greijer, E. Van der Wall, P.J. Van Diest, Mutation analysis of the HIF-1a oxygen-dependent degradation domain in invasive breast cancer. Canc. Genet. Cytogenet. 163, $168-172(2005)$

23. M.M. Vleugel, D. Shvarts, E. van der Wall, P.J. van Diest, p300 and p53 levels determine activation of HIF-1 downstream targets in invasive breast cancer. Hum. Pathol. 37, 1085-1092 (2006)

24. K. Lisy, D.J. Peet, Turn me on: regulating HIF transcriptional activity. Cell Death Differ. 15(4), 642-649 (2008)
25. F. Dayan, D. Roux, M.C. Brahimi-Horn, J. Pouyssegur, N.M. Mazure, The oxygen sensor factor-inhibiting hypoxia-inducible factor-1 controls expression of distinct genes through the bifunctional transcriptional character of hypoxia-inducible factor1alpha. Canc. Res. 66(7), 3688-3698 (2006)

26. S.G. Kroeze, J.S. Vermaat, A. van Brussel, H.H. van Melick, E.E. Voest, T.G. Jonges, P.J. van Diest, J. Hinrichs, J.L. Bosch, J.J. Jans, Expression of nuclear FIH independently predicts overall survival of clear cell renal cell carcinoma patients. Eur. J. Canc. 46(18), 3375-82 (2010)

27. E.Y. Tan, L. Campo, C. Han, H. Turley, F. Pezzella, K.C. Gatter, A. L. Harris, S.B. Fox, Cytoplasmic location of factor-inhibiting hypoxia-inducible factor is associated with an enhanced hypoxic response and a shorter survival in invasive breast cancer. Breast Canc. Res. 9(6), R89 (2007)

28. P.J. Van Diest, J.P.A. Baak, P. Matze-Cok, E.C.M. WisseBrekelmans, C.M. van Galen, P.H.J. Kurver, S.M. Bellot, J. Fijnheer, L.H.M. van Gorp, W.S. Kwee, J. Los, J.L. Peterse, H.M. Ruitenberg, R.F.M. Schapers, M.E.I. Schipper, J.G. Somsen, A.W. P.M. Willig, A.Th. Ariens, Reproducibility of mitosis counting in 2469 breast cancer specimens: Results from the Multicenter Morphometric Mammary Carcinoma Project. Hum. Pathol. 23, 603-607 (1992)

29. C.W. Elston, I.O. Ellis, Pathological prognostic factors in breast cancer. I. The value of histological grade in breast cancer: experience from a large study with long-term follow-up. Histopathology 19, 403-410 (1991)

30. P.J. Van Diest, No consent should be needed for using leftover body material for scientific purposes. BMJ 325, 648-651 (2002)

31. E.H. Gort, A.J. Groot, E. van der Wall, P.J. van Diest, M.A. Vooijs, Hypoxic regulation of metastasis via hypoxia-inducible factors. Curr. Mol. Med. 8(1), 60-67 (2008)

32. E. Metzen, U. Berchner-Pfannschmidt, P. Stengel, J.H. Marxsen, I. Stolze, M. Klinger, W.Q. Huang, C. Wotzlaw, T. Hellwig-Bürgel, W. Jelkmann, H. Acker, J. Fandrey, Intracellular localisation of human HIF-1 alpha hydroxylases: implications for oxygen sensing. J. Cell Sci. 116(Pt 7), 1319-1326 (2003)

33. E.J. Soilleux, H. Turley, Y.M. Tian, C.W. Pugh, K.C. Gatter, A.L. Harris, Use of novel monoclonal antibodies to determine the expression and distribution of the hypoxia regulatory factors PHD-1, PHD-2, PHD-3 and FIH in normal and neoplastic human tissues. Histopathology 47(6), 602-610 (2005)

34. A. Couvelard, L. Deschamps, V. Rebours, A. Sauvanet, K. Gatter, F. Pezzella, P. Ruszniewski, P. Bedossa, Overexpression of the oxygen sensors PHD-1, PHD-2, PHD-3, and FIH Is associated with tumor aggressiveness in pancreatic endocrine tumors. Clin. Canc. Res. 14(20), 6634-6639 (2008)

35. H. Fukuba, T. Takahashi, H.G. Jin, T. Kohriyama, M. Matsumoto, Abundance of aspargynyl-hydroxylase FIH is regulated by Siah-1 under normoxic conditions. Neurosci. Lett. 433(3), 209-214 (2008)

36. H. Fukuba, H. Yamashita, Y. Nagano, H.G. Jin, M. Hiji, T. Ohtsuki, T. Takahashi, T. Kohriyama, M. Matsumoto, Siah-1 facilitates ubiquitination and degradation of factor inhibiting HIF-1alpha (FIH). Biochem. Biophys. Res. Commun. 353(2), 324-329 (2007)

37. X. Zheng, S. Linke, J.M. Dias, X. Zheng, K. Gradin, T.P. Wallis, B.R. Hamilton, M. Gustafsson, J.L. Ruas, S. Wilkins, R.L. Bilton, K. Brismar, M.L. Whitelaw, T. Pereira, J.J. Gorman, J. Ericson, D. J. Peet, U. Lendahl, L. Poellinger, Interaction with factor inhibiting HIF-1 defines an additional mode of cross-coupling between the Notch and hypoxia signaling pathways. Proc. Natl. Acad. Sci. USA 105(9), 3368-3373 (2008)

38. D. Barrick, R. Kopan, The Notch transcription activation complex makes its move. Cell 124(5), 883-885 (2006)

39. S. Bray, A Notch affair. Cell 93(4), 499-503 (1998)

40. J.S. Mumm, R. Kopan, Notch signaling: from the outside in. Dev. Biol. 228(2), 151-165 (2000) 